\title{
Study on the mechanism of houttuynin inducing apoptosis of MCF-7 cells by inhibiting PI3K/AKT signaling pathway
}

\author{
Qian LIU ${ }^{1 *}$ (D), Guangxuan $\mathrm{LIU}^{1}$, Ying $\mathrm{ZHU}^{1}$, Yingyan $\mathrm{CHAO}^{1}$
}

\begin{abstract}
Objective: The paper investigated the effect and molecular mechanism of Houttuynin on breast cancer in vitro, so as to provide clinical basis for the treatment of breast cancer with Houttuynin. Methods: Cell survival rate was measured by MTT assay. Cell apoptosis was detected by flow cytometry and AO/EB double staining method. The expressions of PI3K, AKT, and mTOR proteins and their phosphorylation levels were determined by WB experiment. Results: Houttuynin can significantly inhibit the growth of breast cancer cells and arrest cell cycle in the G2/M phase. Houttuynin induced apoptosis of breast cancer cells through two pathways, namely, mitochondria and death receptors. It was verified by WB experiment that Houttuynin could induce autophagy in breast cancer cells and reduce the expressions of PI3K, AKT, mTOR and other proteins. Conclusion: Houttuynin induced breast cancer cell apoptosis by inhibiting PI3K/AKT signaling pathway, thereby inhibiting the proliferation of breast cancer cells.
\end{abstract}

Keywords: houttuynin; PI3K/AKT; apoptosis.

Practical Application: Houttuynin Inducing Apoptosis of MCF-7 Cells.

\section{Introduction}

Breast cancer is by far one of the most common cancers in women. Breast cancer is not a single disease, but a group of heterogeneous diseases with highly variable clinical behaviors. Pathologists have long recognized this diversity in morphology, which is reflected in various special histological types of breast cancer, with different microscopic manifestations and related clinical results. However, $70 \%$ to $80 \%$ of breast cancers are non-special invasive ductal cancers, which are not a unique entity, but show significant heterogeneity in tumor morphology, basic molecular biology, and prognosis (Godone et al., 2018; Provenzano et al.,2018).

Houttuynin is the main component of Houttuynia, with various pharmacological effects, such as lowering blood sugar, antioxidant, anti-aging, immune enhancement and anti-tumor effects. However, there are no reports of Houttuynin on breast cancer research, so the present study is innovative.

\section{Methods}

\subsection{MTT method to detect the inhibitory effect of Houttuynin on MCF-7 cells}

After cell culture, the cells were administered with Houttuynin of different concentrations $(0,50,100$, and $150 \mu \mathrm{M})$. After 24 and 48 hours, a total of $50 \mu \mathrm{L}$ of $1 \mathrm{mg} / \mathrm{mL}$ MTT solution was replenished into each well. The OD value was detected at $490 \mathrm{~nm}$ with a microplate reader.

\subsection{Flow cytometry to detect apoptosis}

Houttuynin solutions at density of $0,100,150$, and $200 \mu \mathrm{M}$ were added, respectively, to act for 24 hours. The supernatant was removed. The cells were digested with trypsin, then centrifuged and collected. Mixed with Annexin V-FITC to react for 5 to 15 minutes under darkness. Finally, the apoptosis rate was detected by flow cytometry.

\subsection{AO/EB staining}

MCF-7 cells were obtained and digested with trypsin. The cells were collected and centrifuged, then counted on a cell counting plate. The cells were diluted to $2 \times 10^{5}$ cells/well, and evenly inoculated in a 6-well plate. After 8 hours of culture, the cell adherence completed. Following this, Houttuynin solutions of $0,100,150$, and $200 \mu \mathrm{M}$ were added respectively to act for 24 hours. The cells were washed twice with pre-cooled PBS, then added with $\mathrm{AO} / \mathrm{EB}$ mixture $(\mathrm{AO} 100 \mathrm{mg} / \mathrm{mL}$ and $\mathrm{EB}$ $100 \mathrm{mg} / \mathrm{mL}$ ) to stain for 5-10 minutes. The cells were observed and photographed under an inverted fluorescence microscope.

\subsection{WB method to detect the expression of each protein}

The cells were obtained from each group. The protein concentration was quantified by the protein standard BCA method with a microplate reader. Proteins were separated by $12 \%$ SDS-PAGE electrophoresis. The separated protein bands were transferred to PVDF membranes by wet method. First and second antibody incubation. Color development and fixation were conducted by chemiluminescence. 


\subsection{Statistical methods}

All data are expressed as mean \pm standard deviation (mean $\pm \mathrm{SD}$ ). Comparisons between two groups were performed using $t$-tests, and comparisons between multiple groups of data $(>2)$ were conducted using One-way ANOVA. Statistical significance was found at $\mathrm{p}<0.05$. Data were analyzed using Graphpad Prism 5.0 (Graphpad Software. San Diego, CA).

\section{Results and discussion}

\subsection{The inhibitory effect of Houttuynin on MCF-7 proliferation}

As shown in Figure 1, with the accumulation of the time and the dose increase of Houttuynin, the inhibitory effect on breast cancer cells MCF-7 also increased, in a concentration and dose-dependent manner. Compared with the control group, there is a significant difference.

\subsection{Effect of Houttuynin on MCF-7 cell apoptosis}

As shown in Figure 2, MCF-7 cells significantly increased in early and late stages after treatment with Houttuynin, and in

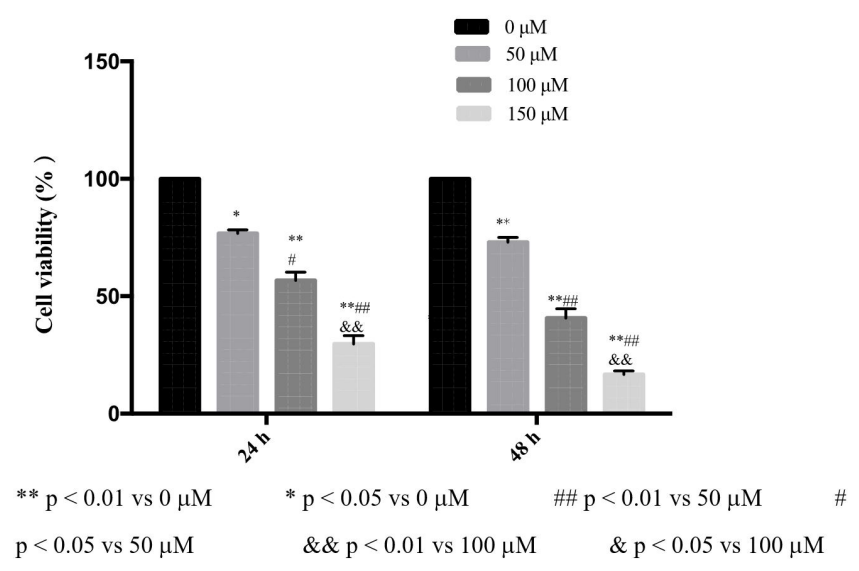

Figure 1. Effect of Houttuynin on the proliferation of MCF-7 cells. a dose-dependent way. Compared with the control group, the proportion of early and late-stage apoptotic MCF-7 cells increased after treatment with Houttuynin at the concentration of $150 \mu \mathrm{M}$.

\subsection{AO/EB staining to detect MCF-7 cell apoptosis}

As the concentration of Houttuynin increased, the number of cells showing green fluorescence in MCF-7 cells decreased significantly, while the number of cells showing red-orange fluorescence increased significantly, and in a dose-dependent manner. As shown in Figure 3.

\subsection{WB method to detect the expressions of various proteins}

As shown in Figure 4, with the increase of Houttuynin concentration, the expressions of cytochrome c, Bax, and caspase- 9 proteins, which are the main members of the mitochondrial apoptosis pathway in MCF-7 cells, were significantly up-regulated. The expression of Bcl-2 protein was significantly reduced, and in a dose-dependent manner. The expression of Fas protein, the main member of the death receptor pathway in MCF-7 cells, and caspase- 8 protein after splicing, were significantly up-regulated.

In order to study the upstream mechanism of Houttuynin on breast cancer, the PI3K/AKT signaling pathway in breast cancer cells was investigated. The expressions of PI3K (Tyr607), AKT (Ser473), mTOR (Ser2448), and Bad (Ser136) proteins and their phosphorylated proteins in MCF-7 cells treated with Houttuynin were analyzed by WB experiments. The experimental results are shown in Figure 5. As the concentration of Houttuynin increased, phosphorylated PI3K protein ( $\mathrm{p}$-PI3K), phosphorylated AKT protein (p-AKT), phosphorylated mTOR protein (P-mTOR), and phosphorylated Bad protein ( $\mathrm{p}$-Bad) expressions were all significantly reduced in MCF-7 cells, and in a dose-dependent way. Compared with the control group, there were significant differences.

To further investigate whether Houttuynin-induced apoptosis and autophagy of breast cancer cells are related to the PI3K/AKT signaling pathway, LY294002 at a concentration of $20 \mu \mathrm{M}$ was used to pre-treat MCF-7 cells for 2 hours, and then $100 \mu \mathrm{M}$ Houttuynin was used. The effects of LY294002-pretreated Houttuynin on the expressions of PI3K, p-PI3K, AKT, p-AKT, mTOR, p-mTOR, Bad, and $\mathrm{p}$-Bad proteins are shown in Figure 6 . The results exhibited that
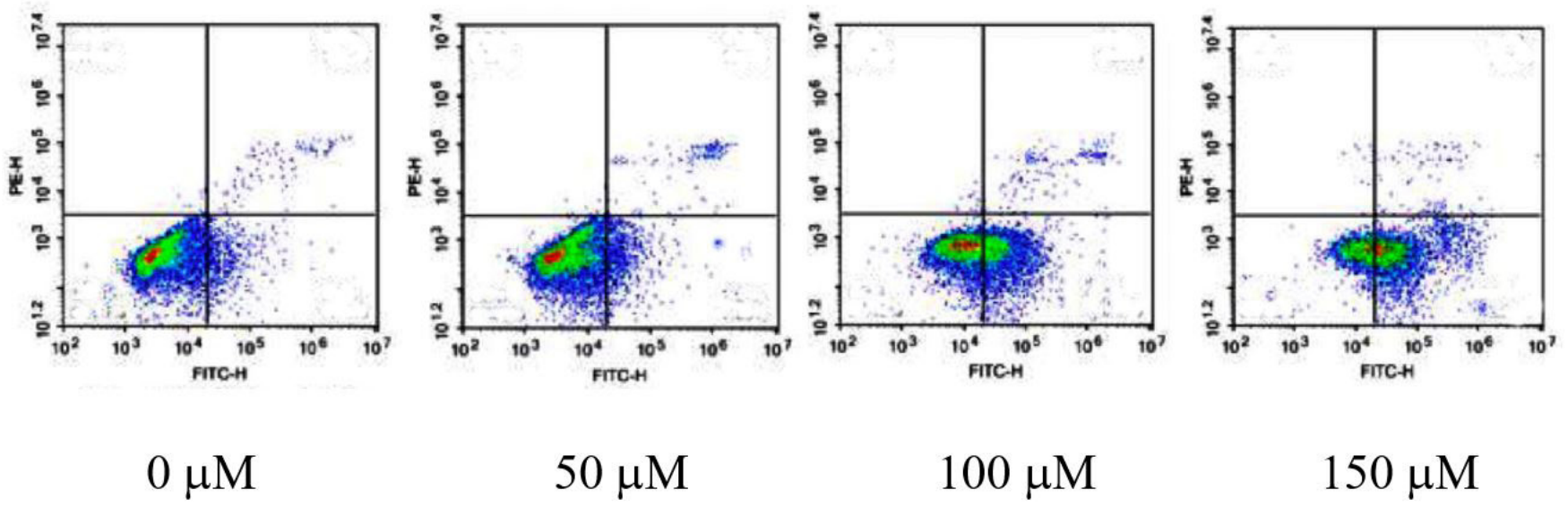

Figure 2. Effect of Houttuynin on MCF-7 cell apoptosis. 
LY294002 significantly reduced the amount of Houttuynin-induced proteins in MCF-7 cells, compared with the Houttuynin-alonetreated breast cancer cells. The expressions of p-PI3K, p-AKT, p-mTOR and p-Bad proteins significantly decreased, while the expression of Bad protein increased, but there was no significant difference in the expressions of $\mathrm{PI} 3 \mathrm{~K}, \mathrm{AKT}$ and $\mathrm{mTOR}$ proteins.

The current treatment methods for breast cancer mainly focus on surgery, chemotherapy, radiotherapy and bio-targeted therapy. Bio-targeted therapy has been a hot topic in breast cancer treatment in recent years. At present, the bio-targeted molecular therapy for breast cancer consists of the following aspects: PI3K/AKT/mTOR
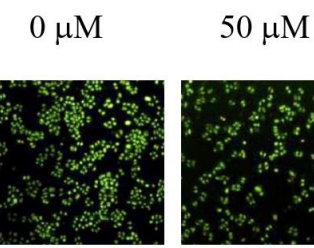

$100 \mu \mathrm{M}$

$150 \mu \mathrm{M}$
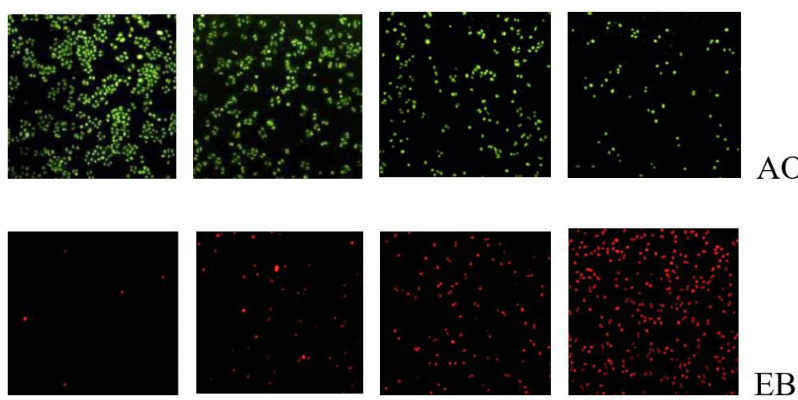

$\mathrm{AO}$
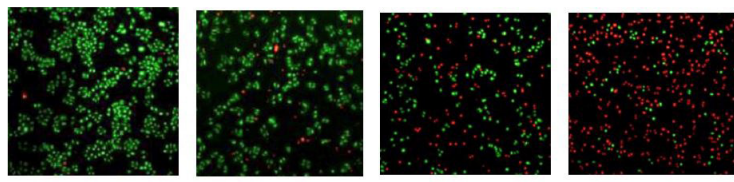

EB

Figure 3. AO/EB staining to detect MCF-7 cell apoptosis.

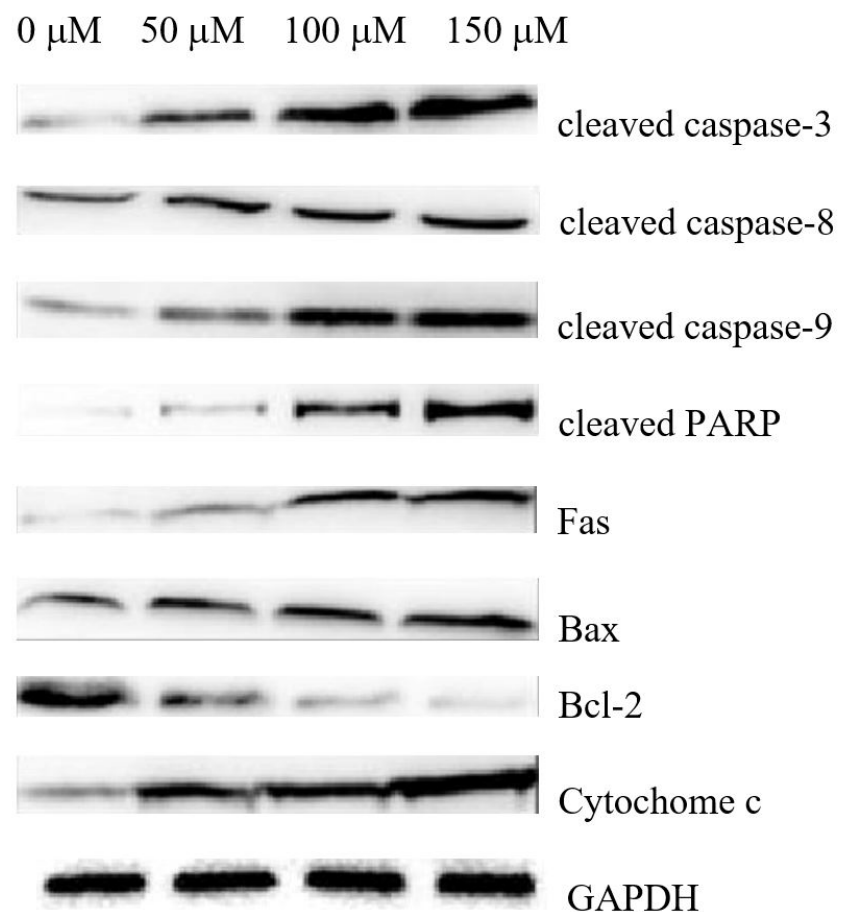

Figure 4. Effect of Houttuynin on related apoptotic proteins.

Merge inhibitors, MAPK inhibitors, JAK/STAT inhibitors, receptor tyrosine kinase inhibitors, androgen receptor inhibitors, PARP inhibitors, immunotherapy and cancer vaccines(Smith et al., 2017; Moo et al., 2018; O’Shaughnessy et al., 2017).

\section{$0 \mu \mathrm{M} \quad 50 \mu \mathrm{M} \quad 100 \mu \mathrm{M} \quad 150 \mu \mathrm{M}$}
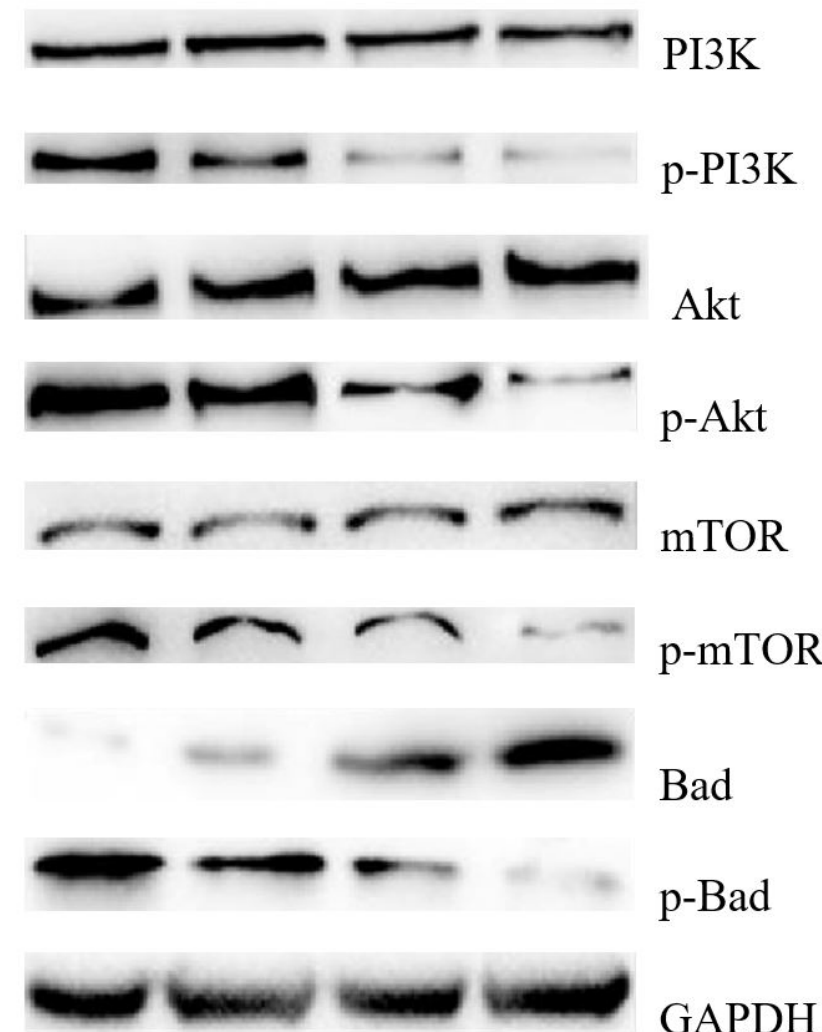

$\mathrm{Bad}$

Figure 5. Effect of Houttuynin on the expressions of PI3K/AKT signaling pathway proteins in MCF-7 cells.

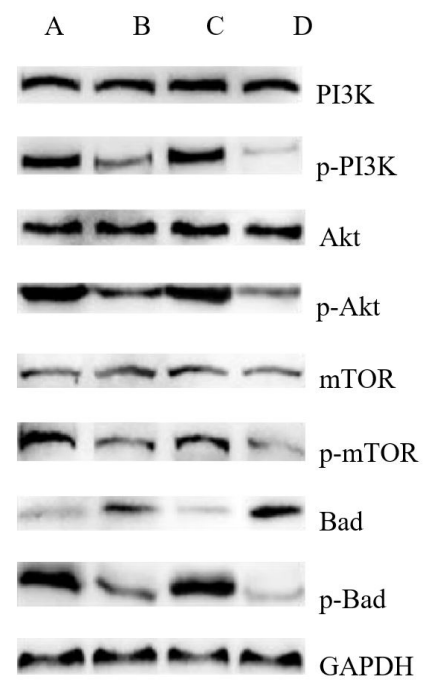

A: $0 \mu \mathrm{M} \quad$ B: $150 \mu \mathrm{M} \quad$ C: LY29002 D: LY29002+ Drug

Figure 6. Effects of LY294002-pretreated Houttuynin on MCF-7 cells. 
$\mathrm{PI} 3 \mathrm{~K} / \mathrm{AKT} / \mathrm{mTOR}$ is the main pathway that regulates cell survival and proliferation, and is the most common signaling pathway in breast cancer. PI3KCA, AKT1, AKT2 and PTEN are very important genes in the PI3K/AKT pathway. The increased mutation rate in cancer patients can lead to abnormal regulation of the PI3K/AKT pathway (Vasiliou \& Diamandis, 2019). Over-activation of the PI3K pathway occurs in $70 \%$ of breast cancer patients, and PIK3CA mutations occur in nearly $30 \%$ of breast cancer patients. Mutations in AKT1 and AKT2 can activate AKT signaling in HR+/luminal breast cancer (Kono et al., 2017; Musella et al., 2018).

AKT is the main downstream target of PI3K, with phosphorylated AKT protein as the active form. The phosphorylation of AKT protein is closely related to apoptosis. AKT activation can promote the phosphorylation of Bad at Ser136 site, thereby reducing the function of Bad protein. Bad is an important pro-apoptotic protein in the $\mathrm{Bcl}-2$ family. It forms a heterodimer with the $\mathrm{Bcl}-2$ protein and then promotes apoptosis together. Phosphorylated Bad protein can bind to 14-3-3 protein, thus preventing Bad protein from binding to $\mathrm{Bcl}-2$ protein on mitochondrial membrane. Therefore, the inhibition of apoptosis by Bad protein phosphorylation is essential (Huang, 2020; Zheng \& Wang, 2020). Previous studies have shown that the PI3K/AKT pathway inhibits mitochondrial-mediated apoptosis in papillary thyroid cancer (PTC) cells by promoting phosphorylation of Bad (Dieci et al., 2018; Esmailpoor et al., 2019).

In this study, MTT, flow cytometry, AO / EB double staining, and Western blot experiments were performed to verify that Houttuynin could significantly inhibit the growth of breast cancer cells. The mitochondria and death receptors were used to induce apoptosis of breast cancer cells. Western blotting experiments have confirmed that Houttuynin can induce autophagy in breast cancer cells. Further studies have demonstrated that Houttuynin can induce apoptosis and autophagy in breast cancer cells by inhibiting the PI3K/AKT signaling pathway.

\section{Conclusion}

These results reveal that Houttuynin can achieve anti-breast cancer efficacy through a variety of anti-cancer molecular mechanisms, with no side effects, and is expected to make up for the current breast cancer chemotherapy strategies.

\section{References}

Godone, R., Leitão, G. M., Araújo, N. B., Castelletti, C. H. M., LimaFilho, J. L., \& Martins, D. B. G. (2018). Clinical and molecular aspects of breast cancer: Targets and therapies. Biomedicine and Pharmacotherapy, 106, 14-34. http://dx.doi.org/10.1016/j. biopha.2018.06.066. PMid:29945114.

Provenzano, E., Ulaner, G. A., \& Chin, S. F. (2018). Molecular classification of breast cancer. PET Clinics, 13(3), 325-338. http:// dx.doi.org/10.1016/j.cpet.2018.02.004. PMid:30100073.
Smith, B. L., Tang, R., Rai, U., Plichta, J. K., Colwell, A. S., Gadd, M. A., Specht, M. C., Austen, W. G. Jr, \& Coopey, S. B. (2017). Oncologic safety of nipple-sparing mastectomy in women with breast cancer. Journal of the American College of Surgeons, 225(3), 361-265. http:// dx.doi.org/10.1016/j.jamcollsurg.2017.06.013. PMid:28728962.

Moo, T. A., Sanford, R., Dang, C., \& Morrow, M. (2018). Overview of breast cancer therapy. PET Clinics, 13(3), 339-354. http://dx.doi. org/10.1016/j.cpet.2018.02.006. PMid:30100074.

O’Shaughnessy, J., Demichele, A., Ma, C. X., Richards, P., Yardley, D. A., Wright, G. S., Kalinsky, K., Steis, R., Diab, S., Kennealey, G., Geschwindt, R., Jiang, W., \& Rugo, H. S. (2017). A randomized, double-blind, phase 2 study of ruxolitinib or placebo in combination with capecitabine in patients with advanced HER2-negative breast cancer and elevated C-reactive protein, a marker of systemic inflammation. Breast Cancer Research and Treatment, 170(3), 547557. http://dx.doi.org/10.1007/s10549-018-4770-6. PMid:29675680.

Vasiliou, S. K., \& Diamandis, E. P. (2019). Androgen receptor: A promising therapeutic target in breast cancer. Critical Reviews in Clinical Laboratory Sciences, 1575643(3), 1-24. http://dx.doi.org/1 0.1080/10408363.2019.1575643. PMid:30821186.

Kono, M., Fujii, T., Lim, B., Karuturi, M. S., Tripathy, D., \& Ueno, N. T. (2017). Androgen receptor function and androgen receptortargeted therapies in breast cancer: a review. JAMA Oncology, 3(9), 1266-1273. http://dx.doi.org/10.1001/jamaoncol.2016.4975. PMid:28301631.

Musella, A., Bardhi, E., Marchetti, C., Vertechy, L., Santangelo, G., Sassu, C., Tomao, F., Rech, F., D’Amelio, R., Monti, M., Palaia, I., Muzii, L., \& Benedetti Panici, P. (2018). Rucaparib: an emerging parp inhibitor for treatment of recurrent ovarian cancer. Cancer Treatment Reviews, 66, 7-14. http://dx.doi.org/10.1016/j.ctrv.2018.03.004. PMid:29605737.

Huang, T., Yang, X., Ji, J., Wang, Q., Wang, H., \& Dong, Z. (2020). Inhibitory effects of tanshinone IIA from Salvia miltiorrhiza Bge on human bladder cancer BIU-87 cells and xenograft in nude mice. Food Sci. Technol, 40(1), 209-214. http://dx.doi.org/10.1590/fst.38818.

Zheng, F., \& Wang, Z. (2020). miRNA-1180 suppresses HCC cell activities via TRAF1/NF- $\kappa \mathrm{B}$ signaling pathway. Food Science and Technology, 40(Suppl. 2), 626-633. http://dx.doi.org/10.1590/fst.26219.

Dieci, M. V., Radosevicrobin, N., Fineberg, S., van den Eynden, G., Ternes, N., Penault-Llorca, F., Pruneri, G., D’Alfonso, T. M., Demaria, S., Castaneda, C., Sanchez, J., Badve, S., Michiels, S., Bossuyt, V., Rojo, F., Singh, B., Nielsen, T., Viale, G., Kim, S. R., Hewitt, S., Wienert, S., Loibl, S., Rimm, D., Symmans, F., Denkert, C., Adams, S., Loi, S., \& Salgado, R. (2018). Update on tumor-infiltrating lymphocytes (TILs) in breast cancer, including recommendations to assess TILs in residual disease after neoadjuvant therapy and in carcinoma in situ: a report of the International Immuno-Oncology Biomarker Working Group on Brea. Seminars in Cancer Biology, 52(Pt 2), 16-25. http://dx.doi.org/10.1016/j.semcancer.2017.10.003. PMid:29024776.

Esmailpoor, A., Ghasemian, A., Dehnavi, E., Peidayesh, H., \& Teimouri, M. (2019). Physalis alkekengi hydroalcoholic extract enhances the apoptosis in mouse model of breast cancer cells. Gene Reports, 15, 100366. http://dx.doi.org/10.1016/j.genrep.2019.100366. 